\title{
OPEN Changes in soil water holding capacity and water availability following vegetation restoration on the Chinese Loess Plateau
}

\begin{abstract}
Yong-wang Zhang ${ }^{1 \bowtie}$, Kai-bo Wang ${ }^{3}$, Jun Wang ${ }^{1}$, Changhai Liu ${ }^{1 \bowtie}$ \& Zhou-ping Shangguan ${ }^{2}$
Changes in land use type can lead to variations in soil water characteristics. The objective of this study was to identify the responses of soil water holding capacity (SWHC) and soil water availability (SWA) to land use type (grassland, shrubland and forestland). The soil water characteristic curve describes the relationship between gravimetric water content and soil suction. We measured the soil water characteristic parameters representing SWHC and SWA, which we derived from soil water characteristic curves, in the $0-50 \mathrm{~cm}$ soil layer at sites representing three land use types in the Ziwuling forest region, located in the central part of the Loess Plateau, China. Our results showed that the SWHC was higher at the woodland site than the grassland and shrubland, and there was no significant difference between the latter two sites, the trend of SWA was similar to the SWHC. From grassland to woodland, the soil physical properties in the $0-50 \mathrm{~cm}$ soil layer partially improved, BD was significantly higher at the grassland site than at the shrubland and woodland sites, the clay and silt contents decreased significantly from grassland to shrubland to woodland and sand content showed the opposite pattern, the soil porosity was higher in the shrubland and woodland than that in the grassland, the soil physical properties across the $0-50 \mathrm{~cm}$ soil layer improved. Soil texture, porosity and bulk density were the key factors affecting SWHC and SWA. The results of this study provide insight into the effects of vegetation restoration on local hydrological resources and can inform soil water management and land use planning on the Chinese Loess Plateau.
\end{abstract}

Soil provides ecosystem services and also benefits society by producing biomass and maintaining biodiversity ${ }^{1}$. However, soil erosion is widespread worldwide, especially in the Loess Plateau region of China, and soil erosion has become a major environmental problem that limits the survival and development of human beings and the sustainable development of the global economy and society ${ }^{2}$. Soil erosion can cause soil degradation, reduce land productivity, threaten agricultural production and food security; furthermore, the environment and socioeconomic development in areas adjacent to erosion regions are affected by pollutants transported by runoff and sediment, which can cause water eutrophication and habitat destruction and intensify drought and waterlogging disasters in downstream areas ${ }^{3}$. Preventing and controlling soil erosion can benefit the environment, provide ecological security, and allow sustainable development and harmony between humans and nature ${ }^{4}$.

Vegetation restoration is an effective measure for preventing and controlling soil erosion. In recent years, with the implementation of China's national policy to return farmland to forest and grassland, soil and water loss on the Loess Plateau has decreased significantly ${ }^{5}$. Soil moisture, as the main factor regulating plant communities, can affect the structure and complexity of the plant community during long-term vegetation restoration and reconstruction. The change in land use following vegetation restoration can alter the root systems of plants and nitrogen fixation, which can lead to changes in the richness and composition of the soil microbial community, improve soil physical properties, and change the soil surface features. Changes in the surface properties of soil inevitably result in changes in other soil properties, such as soil water conductivity, aggregate stability, and particle composition. In addition, the transition among vegetation restoration stages can cause variations in soil water characteristics. The soil water characteristic curve describes the relationship between gravimetric water

\footnotetext{
${ }^{1}$ Shaanxi Key Laboratory of Chinese Jujube, Yan'an University, Yan'an 716000, Shaanxi, People's Republic of China. ${ }^{2}$ State Key Laboratory of Soil Erosion and Dryland Farming on the Loess Plateau, Institute of Soil and Water Conservation, Chinese Academy of Sciences and Ministry of Water Resources, Yangling 712100, Shaanxi, People's Republic of China. ${ }^{3}$ Institute of Earth Environment, Chinese Academy of Sciences, Xi'an 710061, Shaanxi, People's Republic of China. ${ }^{\bowtie}$ email: yongwang19880405@163.com; yadxlch@yau.edu.cn
} 
content, volumetric water content, or degree of saturation and soil suction (or equivalent relative humidity) ${ }^{6}$. Compared with tests in traditional soil mechanics, tests that directly measure unsaturated soil properties are not as easily accessible and are often extremely labor intensive. One tool that has made the analysis of unsaturated soil data simpler and more practical is the soil water characteristic curve $\mathrm{e}^{7,8}$. The soil water characteristic curve can be used to indirectly determine the soil shear strength, permeability, change in water volume, water holding capacity and water availability.

The photosynthesis rate, carbon allocation, plant growth, nutrient cycling and microbial activity have close relationships with the soil water status ${ }^{9}$. How much water a soil can hold against gravity is very important for plant growth because the water retained in the soil can compensate for a lack of precipitation in dry years, but not all of the water held by soil is available for plant growth. However, directly assessing the available water for plant growth is challenging because of the expensive and complicated laboratory measurements required, limiting the availability of data. The soil water holding capacity (SWHC) can be used to estimate the maximum amount of water stored in the soil and reflects the capacity of the soil to provide water for plant growth. The change in land use that occurs during vegetation restoration has been identified as one of the most powerful agents driving environmental change and can explain $>50 \%$ of the variability in water quantity ${ }^{10}$. Vegetation type, plant species ${ }^{11,12}$ and the activities of fungi and bacteria ${ }^{13}$ also influence soil water characteristics. Deforestation and cultivation may cause a decrease in soil infiltration by decreasing porosity and SWHC. Furthermore, changes in land use type may cause changes in the physical and chemical properties of soil and in the soil microbial community ${ }^{14}$. Previous research conducted in the $0-20 \mathrm{~cm}$ soil layer in different vegetation types in the hilly gullied region of the Loess Plateau revealed that the soil water retention curves of all vegetation types exhibited approximate "S" shapes. The ranges of soil available water in the $0-10 \mathrm{~cm}$ and $10-20 \mathrm{~cm}$ soil layers were $22.65-26.80 \%$ and 23.97-28.13\%, respectively, among the different vegetation types, and the soil moisture availability of grass communities and perennial Artemisia communities was greater than that in the annual herbaceous community and less than that of the shrub communities except the Bothriochloa ischaemum community and the Robinia pseudoacacia forest. Furthermore, in the $10-20 \mathrm{~cm}$ soil layer, the soil water capacities of the grass communities and perennial Artemisia communities were higher than that of the annual herbaceous community and lower than that of the shrub community ${ }^{15}$. However, the variation and potential of SWHC and the corresponding influencing factors at different vegetation restoration stages from grassland to shrubland to woodland on the Chinese Loess Plateau are unknown.

All water remaining in the root zone reservoir cannot be taken up by the plant as rapidly as needed because it is held too tightly by the soil particles ${ }^{16}$. Soil water availability (SWA) reflects the dynamic changes of several soil characteristics under the comprehensive actions of atmospheric, crop and soil factors; it can indicate whether soil water can be used by crops and, if so, how readily. SWA is one of the most important factors used to study the soil water environment. Plant roots, soil temperature, plant growth, microbial respiration, substrate availability, stomatal conductance, transpiration and belowground C allocation all have interaction effects with SWA ${ }^{17}$. Nevertheless, information about the responses of soil properties (bulk density (BD), porosity and texture) to SWA and SWHC at different vegetation restoration stages on the Chinese Loess Plateau is currently unknown. Thus, in this study, we hypothesized that the SWA and SWHC varied with long-term natural vegetation restoration ages throughout succession, and the specific aims of the present study were to examine the variation in the soil water characteristic curve at different stages of vegetation restoration, investigate the key soil properties affecting SWHC and SWA and assess the effects of different vegetation restoration stages on SWHC and SWA.

\section{Materials and methods}

Study area. The Ziwuling forest area occupies approximately $23,000 \mathrm{~km}^{2}$ and is the sole secondary forest region remaining on the Chinese Loess Plateau ${ }^{18}$. An intact series of naturally recovering vegetation succession is present on the Loess Plateau. We chose the Ziwuling Forest Region of the Chinese Loess Plateau as the study area to assess the SWHC and SWA of the soil reservoir. Information about the responses of soil properties to SWHC and SWA at different vegetation restoration stages remains lacking. Soil properties, including soil BD, soil texture and soil porosity, etc., are key factors influencing soil water characteristics. For this reason, in our study, we used land use and land cover change (LUCC) over time and adopted some simple assumptions about its impacts on soil water characteristics under a range of vegetation restoration stages. We hypothesized that vegetation restoration stage significantly affects soil $\mathrm{BD}$, porosity, texture and water content and consequently influences soil water characteristics, such as SWHC and SWA. The Lianjiabian Forest Farm $\left(35^{\circ} 03^{\prime}-36^{\circ} 37^{\prime}\right.$ $\mathrm{N}, 108^{\circ} 10^{\prime}-109^{\circ} 18^{\prime} \mathrm{E}$ ) in eastern Gansu Province is in the central part of Ziwuling forest region, with an area of 23,000 $\mathrm{km}^{2}$ and an altitude of 1211-1453 m above sea level (asl) (Fig. 1), figure legend was created using ArcGIS version 10.6, from ArcGIS Software, Inc., Esri USA, https://support.esri.com/en/products/desktop/arcgis-desktop/arcmap/10-6. The dominant soil type is loessal mein soil (Calcaric Regosol, FAO/UNESCO, 1988). The annual mean precipitation of the area is $587 \mathrm{~mm}$, and there is significant seasonal variation in precipitation (Fig. 2). The land uses in the study area include grassland, shrubland and woodland, and natural vegetation restoration has occurred from grassland to shrubland to woodland over a period of approximately 160 years ${ }^{19}$. The recovery times were estimated by counting growth rings and consulting related written sources ${ }^{20}$. The main species at the different vegetation restoration stages are listed in Table 1.

Soil sampling and analysis. Three soil sites (in grassland, shrubland and woodland) were selected, there are five duplicates for grassland, shrubland and woodland. The grassland plots were $2 \times 2 \mathrm{~m}$, the shrubland plots were $5 \times 5 \mathrm{~m}$, and the woodland plots were $20 \times 20 \mathrm{~m}$. Soil samples were collected at five depths below the soil surface $(10,20,30,40$, and $50 \mathrm{~cm})$ in each plot. To construct the soil water characteristic curves under various suction states $(0,0.1,0.2,0.4,0.6,0.8,1.0,1.5,2.0,4.0,6.0$, and $10.0 \mathrm{bar})$, samples were first saturated for $24 \mathrm{~h}$ 


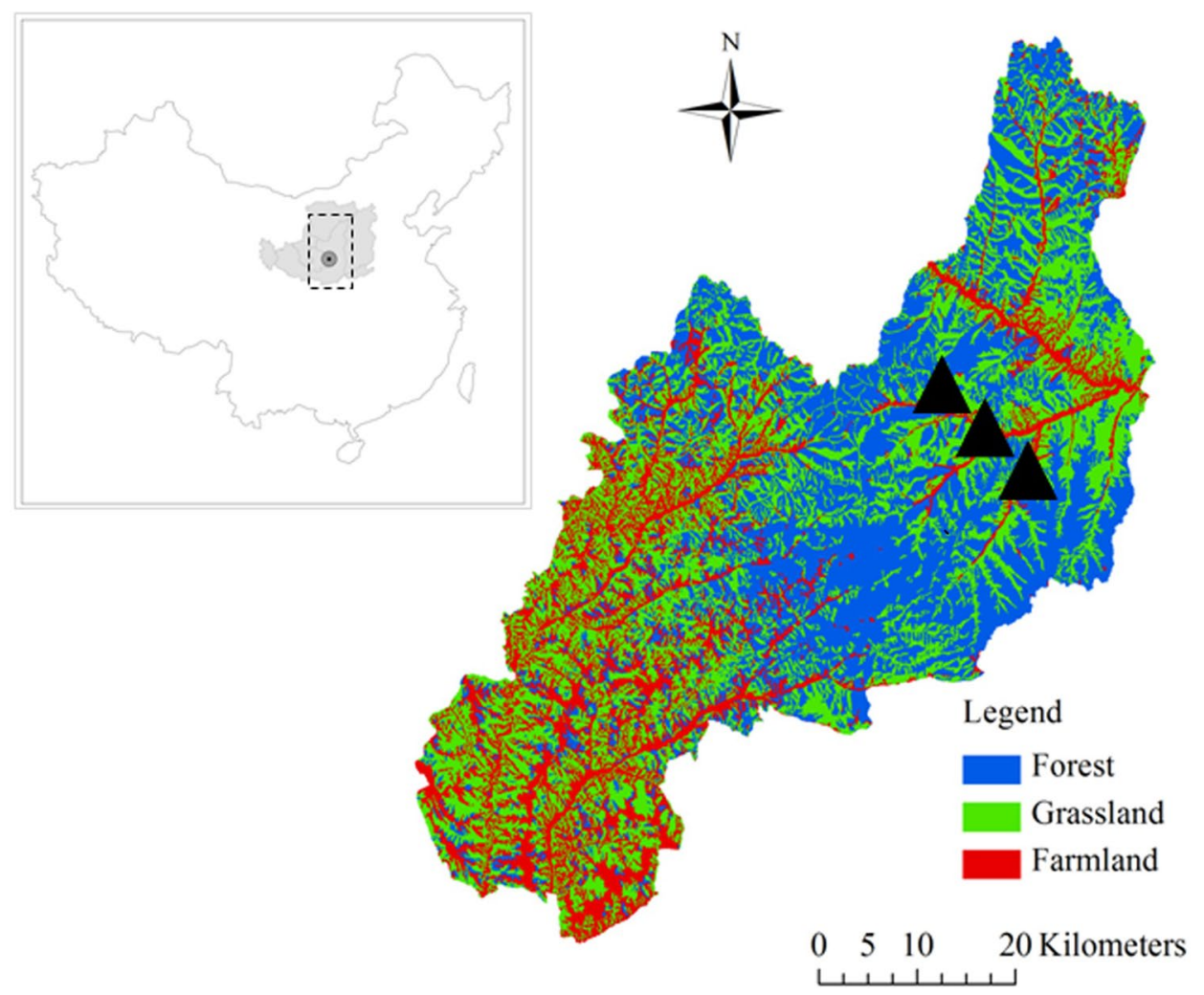

Figure 1. Land use map in the study area. It was created using ArcGIS version 10.6, from ArcGIS Software, Inc., Esri USA, https://support.esri.com/en/products/desktop/arcgis-desktop/arcmap/10-6.

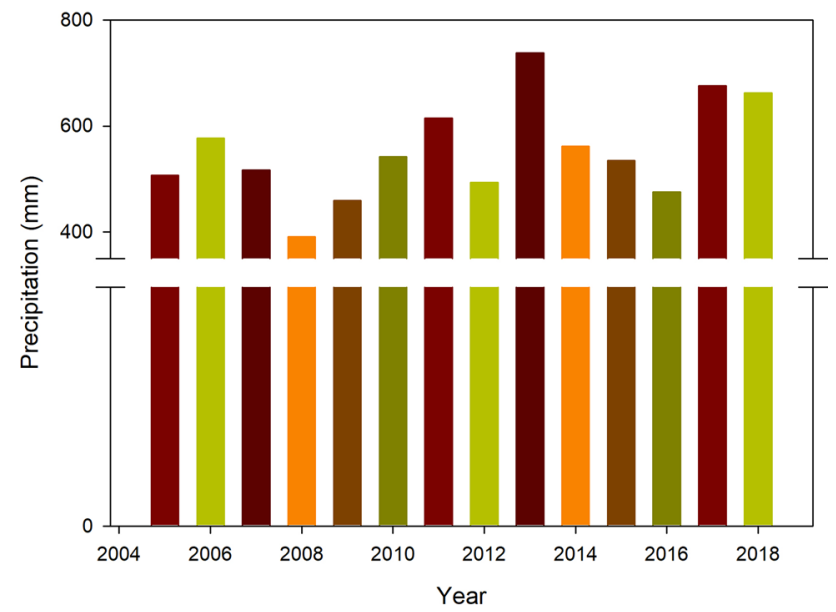

Figure 2. Precipitation in the study area.

\begin{tabular}{|l|c|c|l|l|l|l|l|}
\hline $\begin{array}{l}\text { Vegetation restoration } \\
\text { stage }\end{array}$ & Latitude (N) & Longitude (E) & Altitude (m) & Aspect & Slope $\left(^{\circ}\right)$ & Coverage (\%) & Main plant species \\
\hline G (30 a) & $36^{\circ} 05^{\prime} 08.8^{\prime \prime}$ & $108^{\circ} 31^{\prime} 38.9^{\prime \prime}$ & 1365 & $\mathrm{NE}$ & 8 & 85 & B. ischaemum \\
\hline $\mathrm{S}(50$ a) & $36^{\circ} 04^{\prime} 14.4^{\prime \prime}$ & $108^{\circ} 32^{\prime} 01.4^{\prime \prime}$ & 1354 & $\mathrm{NE}$ & 18 & 90 & H. rhamnoides \\
\hline $\mathrm{W}(160$ a) & $36^{\circ} 02^{\prime} 57.5^{\prime \prime}$ & $108^{\circ} 32^{\prime} 13.7^{\prime \prime}$ & 1449 & $\mathrm{NE}$ & 18 & 95 & Q. liaotungensis \\
\hline
\end{tabular}

Table 1. Geographical and vegetation characteristics at different vegetation restoration stages in the Ziwuling forest region of the Loess Plateau. G represents grassland, S represents shrubland, and W represents woodland. The numbers in parentheses are the years since cropland abandonment. 

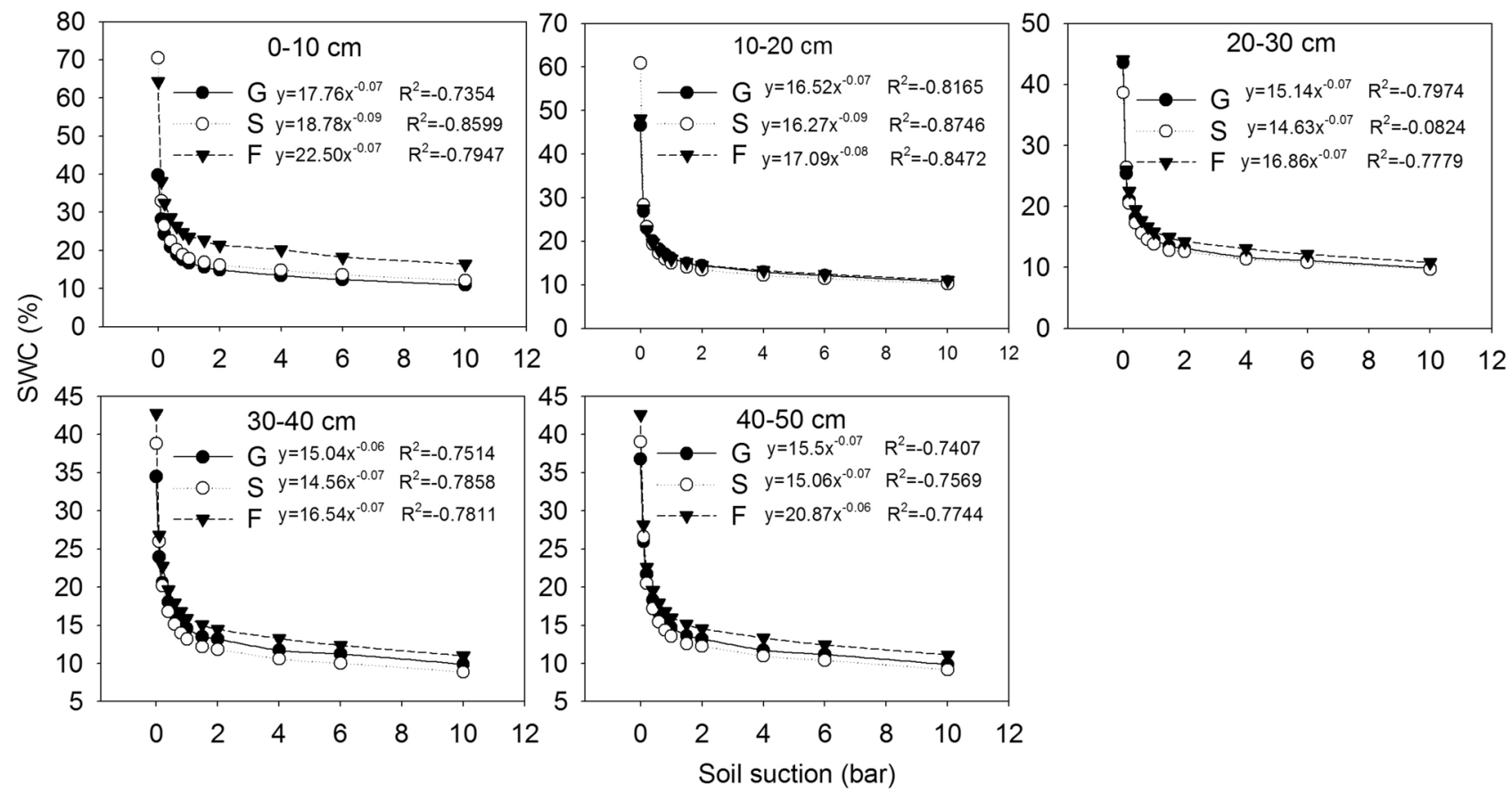

Figure 3. Soil water characteristic curves at different soil depths $(0-10 \mathrm{~cm}, 10-20 \mathrm{~cm}, 20-30 \mathrm{~cm}, 30-40 \mathrm{~cm}$ and $40-50 \mathrm{~cm})$ at different vegetation restoration stages. G, $S$ and $W$ are defined as in Table 1.

and then weighted to determine the soil water content at saturation before submitting them to water extraction by centrifugation ${ }^{21}$ with a Hitachi CR21G centrifuge at a temperature of $20^{\circ} \mathrm{C}$. Soil BD was measured using the oven-dried weight method with the core sampler ${ }^{22}$. The soil saturated moisture content, field moisture capacity and wilting water content were used to calculate the total porosity, inactive porosity, aeration porosity and capillary porosity ${ }^{23}$.

Soil water characteristic parameters. The soil water characteristic parameter A obtained from the soil water characteristic curves was calculated by the following power function empirical equation:

$$
\theta=A S^{-B}
$$

where $\theta$ is the gravimetric soil water content (\%), $\mathrm{S}$ is the soil suction (bar), and A is the SWHC.

Employing the equation above, we measured soil water content at a potential of -20 bar for the wilting point, -0.3 bar for the field capacity, and -10 bar for the critical point of the rapid available water and slow available water. The rapid available water content was calculated as the soil water content under suction from -0.3 to -10 bar, the slow available water content was calculated as the soil water content under suction from - 10 to -20 bar, the total available water content was calculated as the sum of rapid available water content and rapid available water content, and the unavailable water content was calculated as the soil water content under suction of -20 bar $^{16,24}$.

Data analysis. One-way ANOVA was conducted to test the significance of differences in the soil water characteristics among the different vegetation restoration stages. Statistical analyses were performed with the SPSS software package (Version 16.0 for Windows; SPSS, Inc., USA). The regression equations were fit with a modified three parameter exponential decay using SigmaPlot version 10.0, from Systat Software, Inc., San Jose California USA, www.systatsoftware.com. $P<0.05$ was considered statistically significant.

\section{Results}

SWA. Soil water characteristic curves at different soil depths $(0-10 \mathrm{~cm}, 10-20 \mathrm{~cm}, 20-30 \mathrm{~cm}, 30-40 \mathrm{~cm}$ and $40-50 \mathrm{~cm}$ ) in different vegetation restoration stages are shown in Fig. 3. With increasing suction, the soil water content in each soil layer decreased, and when the suction reached 2 bar, the decreasing trend of the soil water content stabilized at all vegetation restoration stages. During the dehydration process, in the soil layers above $20 \mathrm{~cm}$, the soil water characteristic curve was highest at the grassland site, second highest at the shrubland site, and lowest at the woodland site. However, below $20 \mathrm{~cm}$, the curve was lowest at the shrubland site. The values of the soil water characteristic parameter $\mathrm{A}$ in the different soil layers at the different vegetation restoration stages are shown in Fig. 4. Parameter A was significantly higher at the woodland site than at the grassland and shrubland sites in all of the soil layers except the 10-20 cm layer $(P<0.05)$, and there was no significant difference in this parameter between the grassland and shrubland in any of the soil layers from 0 to $50 \mathrm{~cm}(P>0.05)$, this indicated that SWHC was higher at the woodland site than the grassland and shrubland, and there was no significant difference between the latter two sites. 


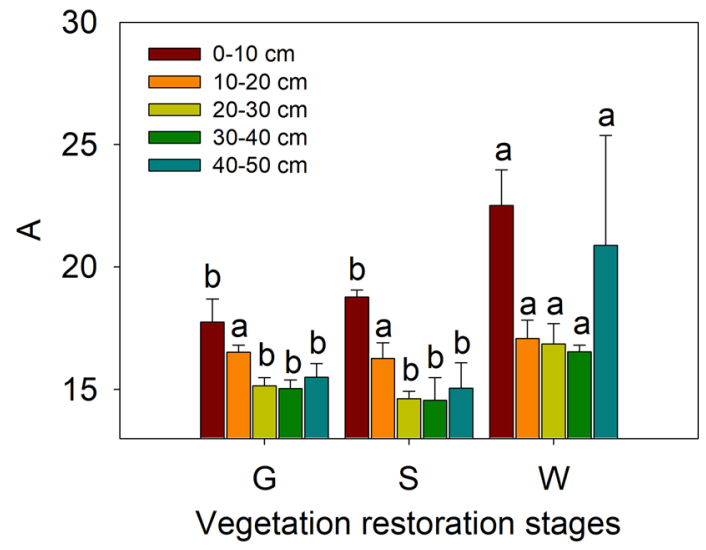

Figure 4. Soil water characteristic parameter A in the different soil layers at different vegetation restoration stages (see Table 1). The values are in the form of means \pm SEs, and the sample size (n) is 5 . The different lowercase letters above the bars indicate significant differences within a soil layer among the different vegetation restoration stages $(P<0.05)$.

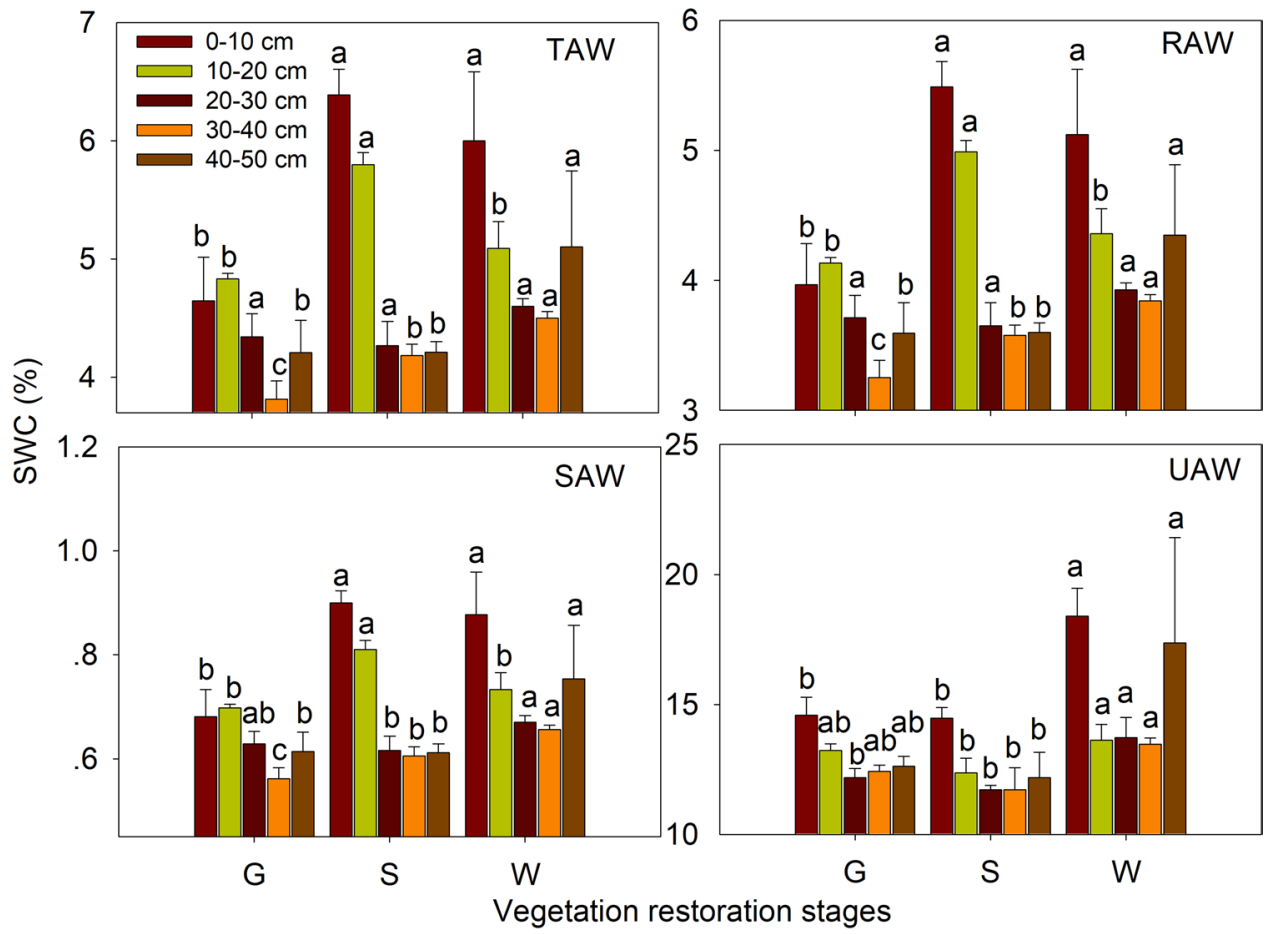

Figure 5. Total available water content (TAW), rapid available water content (RAW), slow available water content (SAW) and unavailable water content (UAW) in the different soil layers at different vegetation restoration stages (see Table 1 ). The values are in the form of means \pm SEs, and the sample size (n) is 5 . The different lowercase letters above the bars indicate significant differences within a soil layer among the different vegetation restoration stages $(P<0.05)$.

Total available water content, rapid available water content, slow available water content and unavailable water content in the different soil layers at the different vegetation restoration stages are shown in Fig. 5 . In the $0-10 \mathrm{~cm}$ soil layer, the total available water content at the grassland site was significantly lower than the corresponding contents at the shrubland and woodland sites $(P<0.05)$, and no significant difference was identified between shrubland and woodland. In the $10-20 \mathrm{~cm}$ soil layer, total available water content at the shrubland site was obviously higher than the corresponding contents at the two other sites representing different vegetation restoration stages $(P<0.05)$, and no difference was detected between grassland and woodland. In the 20-30 cm soil layer, no significant difference was found among any of the three vegetation restoration stages; in the $30-40 \mathrm{~cm}$ soil layer, total available water content increased clearly from grassland to shrubland to woodland $(P<0.05)$. In the $40-50 \mathrm{~cm}$ soil layer, total available water content was markedly higher at the woodland site than at the grassland 


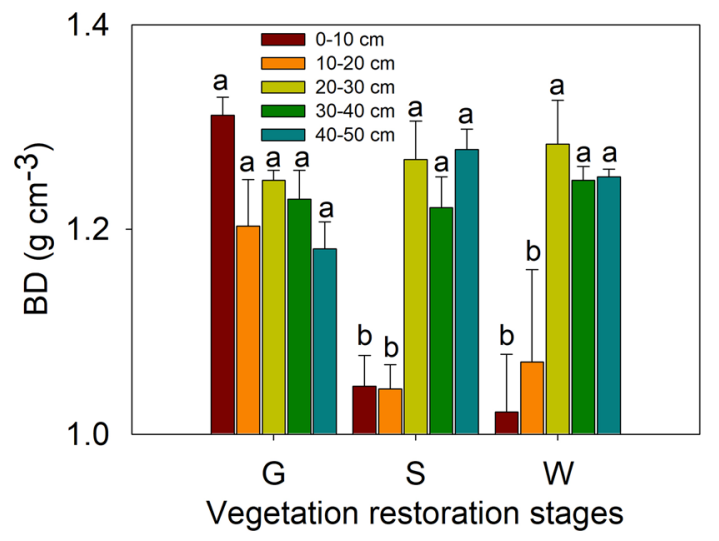

Figure 6. Soil bulk densities (BDs) in the different soil layers at different vegetation restoration stages (see Table 1). The values are in the form of means \pm SEs, and the sample size (n) is 5 . The different lowercase letters above the bars indicate significant differences within a soil layer among the different vegetation restoration stages $(P<0.05)$.

and shrubland sites $(P<0.05)$, and no significant difference between the latter two sites, representing different vegetation restoration stages, was found, in general, the SWA was higher at the woodland site than the grassland and shrubland, and there was no significant difference between the latter two sites, the trend of SWA was similar to the SWHC. Furthermore, the variations of rapid available water content and slow available water content in the $0-50 \mathrm{~cm}$ soil layer were generally similar to those of total available water content. However, unavailable water content in the $0-50 \mathrm{~cm}$ soil layer was highest in woodland among the three land use types $(P<0.05)$, and there was no clear difference between the grassland and shrubland.

Soil properties related to SWA. The values of soil BD in the different soil layers at the different vegetation restoration stages are shown in Fig. 6 . In the $0-10$ and 10-20 cm soil layers, BD was significantly higher at the grassland site than at the shrubland and woodland sites $(P<0.05)$, and no obvious difference among the three vegetation restoration stages was observed in the soil layers below $20 \mathrm{~cm}$. The contents of clay $(<0.002 \mathrm{~mm})$, silt $(0.002-0.02 \mathrm{~mm})$ and sand $(0.02-2 \mathrm{~mm})$ in the different soil layers at the different vegetation restoration stages are shown in Fig. 7. The distribution of soil particle size significantly varied among the different vegetation restoration stages. In the $0-10 \mathrm{~cm}$ soil layer, the clay and silt contents decreased significantly from grassland to shrubland to woodland $(P<0.05)$; however, sand showed the opposite pattern, and both silt and sand varied slightly from shrubland to woodland $(P>0.05)$. In the $10-20$ and $20-30 \mathrm{~cm}$ soil layers, clay content was highest at the grassland site, followed by the woodland site, and lowest at the shrubland site, and silt content was lowest and sand content was highest in shrubland. In the 30-40 cm soil layer, clay content was similar between the shrubland and woodland sites and lower at both these sites than at the grassland site $(P<0.05)$. In addition, in this layer, both the silt content and sand content were similar between the grassland and shrubland; the former was highest and the latter was lowest in the woodland. In the $40-50 \mathrm{~cm}$ soil layer, no clear difference was evident among the different vegetation restoration stages.

The soil porosity parameters in the different soil layers at the different vegetation restoration stages are shown in Fig. 8. In the $0-10 \mathrm{~cm}$ soil layer, soil total porosity, aeration porosity and capillary porosity were higher in shrubland than in grassland and woodland $(P<0.05)$, whereas inactive porosity exhibited the opposite pattern, being lowest in shrubland. None of these parameters significant differed between grassland and woodland. In the $10-20 \mathrm{~cm}$ soil layer, total porosity and capillary porosity were lower at the woodland site than at the grassland and shrubland sites. Furthermore, in this layer, inactive porosity was lowest at the shrubland site, and aeration porosity was highest at the shrubland site, followed by the grassland site, and lowest at the woodland site. In the 20-30 cm soil layer, total porosity, inactive porosity and capillary porosity were higher in woodland than in grassland and shrubland, while aeration porosity varied slightly among the different vegetation restoration stages $(P>0.05)$. In the $30-40 \mathrm{~cm}$ soil layer, total porosity, inactive porosity, aeration porosity and capillary porosity were highest in woodland and lowest, except for inactive porosity, in grassland. In the 40-50 cm soil layer, total porosity and capillary porosity were higher in shrubland $(P<0.05)$ than in the other land use types, and no significant difference was observed between grassland and woodland. In this layer, inactive porosity was highest and aeration porosity was lowest in woodland; however, neither obviously differed between grassland and shrubland. In general, the soil porosity was higher in the shrubland and woodland than that in the grassland.

Relationship between SWA and soil properties. Pearson's correlation coefficients among the soil water characteristic parameter A and soil properties are shown in Table 2. Across the three vegetation restoration stages, in the $0-50 \mathrm{~cm}$ soil layer, parameter A, total available water content, rapid available water content, slow available water content, and unavailable water content showed highly significant and positive relationships $(P<0.01)$ (Table 2). Total available water content, rapid available water content, slow available water content 


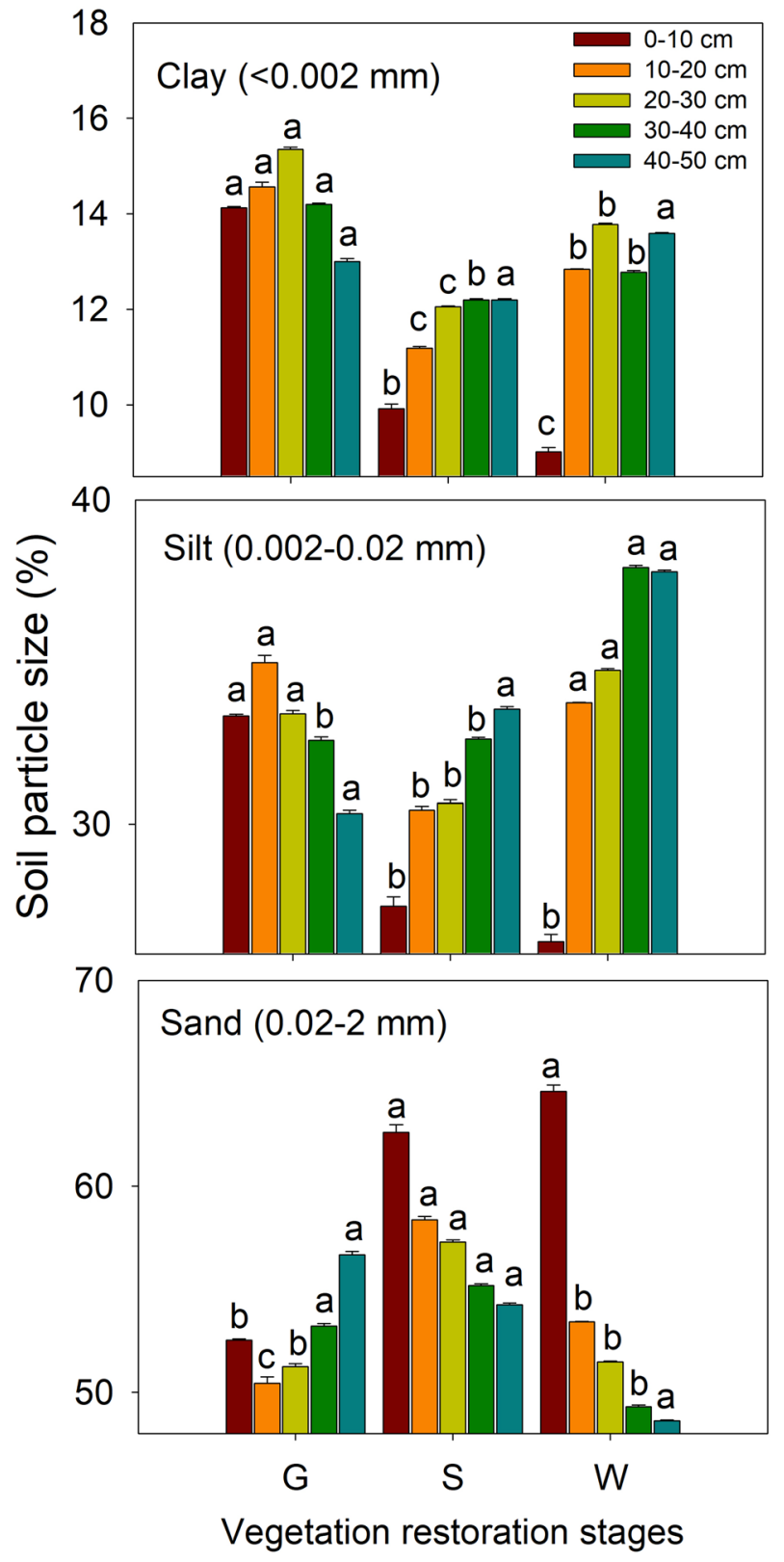

Figure 7. The contents of clay $(<0.002 \mathrm{~mm})$, silt $(0.002-0.02 \mathrm{~mm})$ and sand $(0.02-2 \mathrm{~mm})$ in the different soil layers at different vegetation restoration stages (see Table 1 ). The values are in the form of means \pm SEs, and the sample size $(\mathrm{n})$ is 5 . The different lowercase letters above the bars indicate significant differences within a soil layer among the different vegetation restoration stages $(P<0.05)$.

and unavailable water content were significantly and positively related to each other $(P<0.05)$. Furthermore, the relationship between $\mathrm{A}$ and inactive porosity was significant and positive $(P<0.05)$. Both total available water content and rapid available water content were strongly and positively related to both aeration porosity and capillary porosity $(P<0.01)$ and highly significantly and negatively related to clay content and $\mathrm{BD}(P<0.01)$. Rapid available water content was positively related to sand content $(P<0.05)$, total porosity $(P<0.01)$, aeration porosity $(P<0.05)$ and capillary porosity $(P<0.01)$ and negatively related to clay content and $\mathrm{BD}(P<0.01)$. Unavailable water content was highly and positively related to inactive porosity $(P<0.01)$. Highly significant and positive relationships were observed among clay content, silt content and $\mathrm{BD}(P<0.01)$; however, sand content and BD were highly significantly negatively related $(P<0.01)$ (Table 2$)$. 


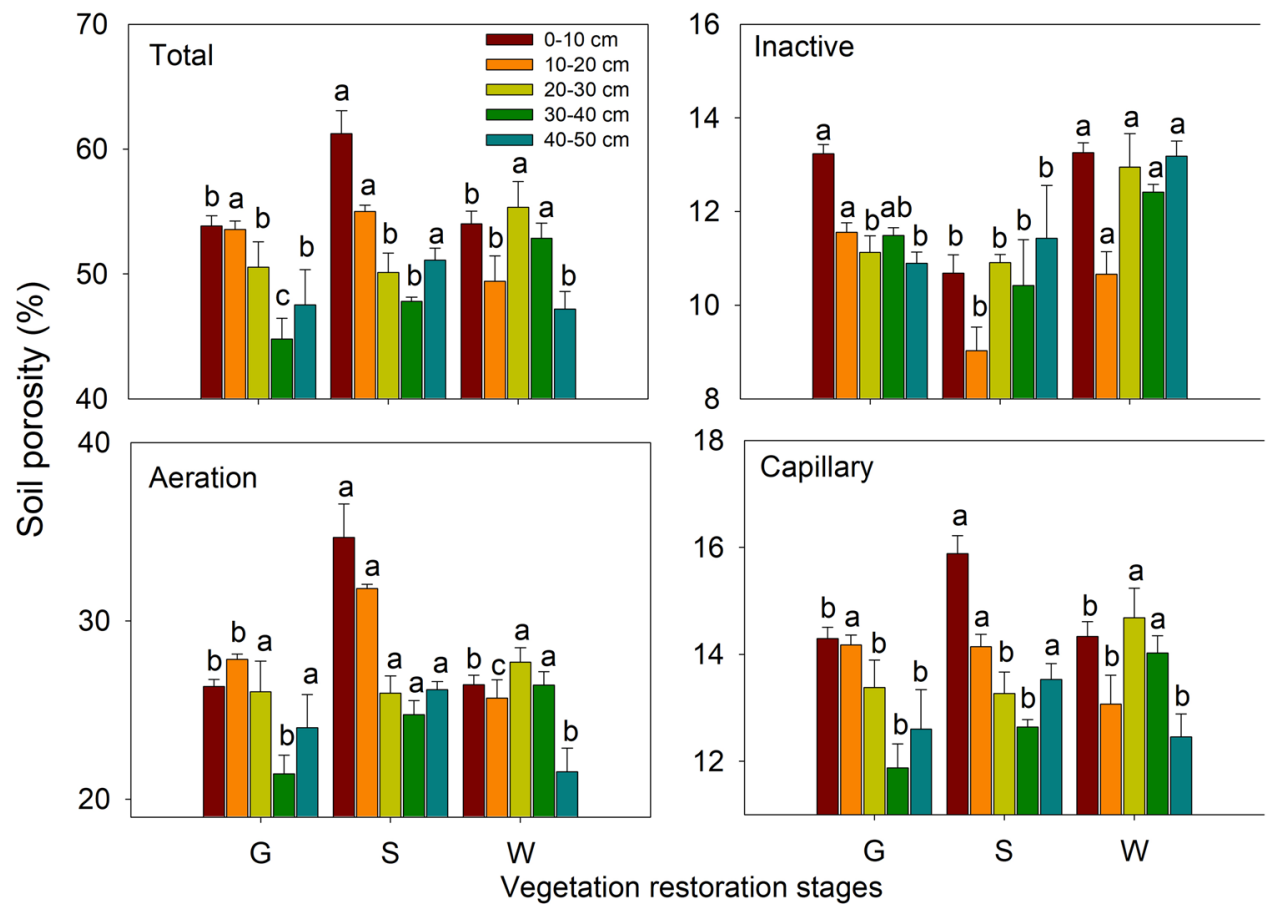

Figure 8. Soil total porosity, inactive porosity, aeration porosity and capillary porosity in the different soil layers at different vegetation restoration stages (see Table 1 ). The values are in the form of means \pm SEs, and the sample size $(\mathrm{n})$ is 5 . The different lowercase letters above the bars indicate significant differences within a soil layer among the different vegetation restoration stages $(P<0.05)$.

\begin{tabular}{|c|c|c|c|c|c|c|c|c|c|c|c|c|}
\hline & A & TAW & RAW & SAW & UAW & Clay & Silt & Sand & TP & IP & AP & $\mathrm{CP}$ \\
\hline A & 1 & & & & & & & & & & & \\
\hline TAW & $0.724^{* *}$ & 1 & & & & & & & & & & \\
\hline RAW & $0.713^{* *}$ & $1.000^{* *}$ & 1 & & & & & & & & & \\
\hline SAW & $0.787^{\star *}$ & $0.995^{* *}$ & $0.994^{* *}$ & 1 & & & & & & & & \\
\hline UAW & $0.986^{* *}$ & $0.597^{*}$ & $0.585^{*}$ & $0.672^{* *}$ & 1 & & & & & & & \\
\hline Clay & -0.453 & $-0.686^{\star *}$ & $-0.687^{* *}$ & $-0.678^{\star *}$ & -0.358 & 1 & & & & & & \\
\hline Silt & -0.191 & -0.484 & -0.487 & -0.462 & -0.103 & $0.712^{\star \star}$ & 1 & & & & & \\
\hline Sand & 0.302 & $0.595^{\star}$ & $0.597^{\star}$ & $0.576^{*}$ & 0.206 & $-0.871^{* *}$ & $-0.965^{* *}$ & 1 & & & & \\
\hline $\mathrm{TP}$ & 0.340 & $0.721^{* *}$ & $0.724^{\star *}$ & $0.695^{* *}$ & 0.219 & -0.453 & -0.347 & 0.412 & 1 & & & \\
\hline IP & $0.576^{\star}$ & -0.053 & -0.066 & 0.035 & $0.682^{* \star}$ & 0.166 & 0.320 & -0.286 & 0.011 & 1 & & \\
\hline $\mathrm{AP}$ & 0.099 & $0.696^{* *}$ & $0.705^{* *}$ & $0.638^{*}$ & -0.055 & -0.488 & -0.446 & \begin{tabular}{|l|l|}
0.494 \\
\end{tabular} & $0.920^{* *}$ & -0.381 & 1 & \\
\hline $\mathrm{CP}$ & 0.353 & $0.679^{* *}$ & $0.682^{\star *}$ & $0.660^{* *}$ & 0.244 & -0.422 & -0.318 & 0.380 & $0.994^{* *}$ & 0.095 & $0.879^{* *}$ & 1 \\
\hline BD & -0.441 & $-0.796^{* *}$ & $-0.799^{* *}$ & $-0.775^{\star *}$ & -0.317 & $0.711^{\star *}$ & $0.651^{* *}$ & $-0.720^{* *}$ & -0.376 & 0.402 & -0.510 & -0.322 \\
\hline
\end{tabular}

Table 2. Pearson's correlations between soil water characteristic parameters and properties. $A$ soil water characteristic parameter, TAW total available water content, $R A W$ rapid available water content, $S A W$ slow available water content, $U A W$ unavailable water content, $T P$ total porosity, $I P$ inactive porosity, $A P$ aeration porosity, $C P$ capillary porosity, $B D$ bulk density. ${ }^{\star}$ Correlation is significant at the 0.05 level (2-tailed).

${ }^{* *}$ Correlation is significant at the 0.01 level $(2$-tailed).

\section{Discussion}

In our study, soil water characteristic curves were generated by the dehydration process, and the curve for the grassland site was higher than the curves for the shrubland and woodland sites. This finding indicated that soil water content in $0-50 \mathrm{~cm}$ soil layers at the grassland site was higher than that at the shrubland and woodland sites; Yang et al. ${ }^{25}$ obtained similar findings. This difference may be because soils at the grassland site had higher clay and silt contents and a lower sand content than the soils at the shrubland and woodland sites (Fig. 7); clay particles absorb water more than sand particles ${ }^{7}$. Another reason may be that the soils at the woodland site tended 
to have lower water contents because of the higher root densities of trees and the resulting greater transpiration ability compared with that of grasses ${ }^{20}$.

The type of land use pattern affects the balance of soil material composition and SWHC. SWHC is affected by soil texture and organic carbon content and soil characteristics, such as pore characteristics. In this study, the soil water characteristic parameter A (Fig. 4) was highest at the woodland site, indicating that SWHC in the $0-50 \mathrm{~cm}$ soil layer was strongest at this site. This finding might have been due to a greater amount of soil water absorbed by roots in woodland, as there are higher root densities in woodland than in grassland ${ }^{20}$. Furthermore, there may have been more soil water stored within inactive pores in grassland, with inactive porosity increasing and $\mathrm{BD}$ decreasing with increasing $\mathrm{A}$ (Table 2). A was lower, i.e., the SWHC was weaker, in the grassland sites. Another reason is that the scarce vegetation at the grassland site may have led to the compaction of the surface soil layer, causing precipitation to be readily converted to surface runoff and decreasing the permeation of precipitation into the soil ${ }^{26}$. Thus, inactive porosity and BD may be the key soil properties affecting SWHC at different vegetation restoration stages.

The SWA status can limit the root and microbial activities ${ }^{27,28}$ and affect substrate availability, belowground carbon allocation and plant growth; accordingly, it exerts direct or indirect effects on microbial respiration and plant roots ${ }^{17}$. From the grassland to the woodland, the available water content was drastically increased in $0-50 \mathrm{~cm}$ soil layers, the reason is that the clay content was decreasing and the sand content was increasing during the vegetation restoration, this finding was agreement with the results of $\mathrm{Li}$ et al. ${ }^{15}$. Besides, the available water content correlated positively with sand content and negatively with clay content, this indicated that soil texture was improved during the vegetation restoration ${ }^{29}$, which caused the increase in SWA. This is also because of the increasing soil porosity in the long-term vegetation restoration. The increase of SWA was induced by the increase of the soil porosity which can improve the soil water storage and retaining capacity ${ }^{30}$, these findings are in agreement with those of Udawatta and Anderson ${ }^{31}$. Soil water storage can be drastically affected by the change of vegetation types, for instance, soil water content significantly decreased because of the increase of tree biomass ${ }^{32}$. Along with the vegetation restoration, the soil water storage remarkably decreased ${ }^{33}$ due to the decrease of soil water content which can be significantly affected by the vegetation types and structures ${ }^{34}$. Different vegetation types have the different root systems and transpiration which can lead the large spatial variation. Besides, soil moisture reduced remarkably after vegetation restoration, and it was varied significantly in the deep soil layers and slightly in the surface soil layers among different vegetation types ${ }^{35}$. The study showed that the soil water storage reduced drastically during the vegetation restoration above $500 \mathrm{~cm}$ soil layers due to the decreasing soil water content. The soil water storage exhibits a significant positive relationship with the soil moisture. In our previous study, $\mathrm{BD}$ in the $0-50 \mathrm{~cm}$ soil layers declined during vegetation restoration, from this we can find the soil physical properties were polished up partly in this process ${ }^{36}$. Nevertheless, BDs in the surface soil layers had no evident differences between the different vegetation types (the succession ages were $<30$ years), showing that soil physical properties would never be improved until the natural vegetation succession ages were more than 30 years $^{29}$. Furthermore, the change in soil sand content was consistent with that of BD; however, the change in soil porosity was the opposite. This finding indicates that the soil degradation caused by the desertification is not easy to turn back rapidly ${ }^{36}$. In addition, the decrease in BD from grassland to shrubland to woodland (Fig. 6) improved the physical properties of the soil in the $0-50 \mathrm{~cm}$ layer to some extent, which is consistent with the findings of Wang et al. ${ }^{36}$; these improvement in turn increased the SWA, and a highly significant negative relationship was observed between BD and each of total available water content, rapid available water content and slow available water content (Table 2). Therefore, soil texture, porosity and BD are the crucial factors affecting SWA.

As the land serves as the carbon source and the carbon sink, the soil function was altered by the change in land use type over the course of the natural vegetation restoration ${ }^{37}$. In previous research, the soil organic carbon (SOC) increased gradually following vegetation succession from grassland to shrubland to woodland, and soil water storage showed a negative relationship with soil organic storage $e^{38}$. Zhao et al. ${ }^{30}$ reported that the importance of organic matter is significant during the process of soil aggregate formation, as it acts as the coagulating substance, and different soil solid states with different porosities result from different soil aggregate bindings caused by different organic matter components. With the accumulation of soil organic matter over the course of natural vegetation restoration, the soil porosity characteristics are inevitably affected, as reported by Deng et al. ${ }^{37}$. Furthermore, Zhao et al. ${ }^{30}$ demonstrated that soil porosity is one of the most important factors affecting the soil reservoir following the natural vegetation restoration on the Chinese Loess Plateau. Soil $\mathrm{N}$ and $\mathrm{P}$ also showed negative relationships with soil water storage; in previous research, such patterns were attributed to increases in leaf $\mathrm{N}$ and $\mathrm{P}$, which are transformed to soil $\mathrm{N}$ and $\mathrm{P}$, over the course of vegetation restoration ${ }^{33}$. Luo et al..$^{39}$ showed that $\mathrm{N}$ dynamics are the main factor regulating soil carbon sequestration; furthermore, one of the most common factors limiting crop production is $\mathrm{N}$. Therefore, soil C, N and P are important chemical factors affecting the soil water characteristics during the process of vegetation restoration, with soil physical properties also affecting these characteristics.

\section{Conclusions}

On the Loess Plateau, the soil water characteristics varied from grassland to shrubland to woodland, representing different vegetation restoration stages. The SWHC, as measured by the soil water characteristic parameter A derived from the soil water characteristic curves, was higher at the woodland site than the grassland and shrubland, and there was no significant difference between the latter two sites, the trend of SWA was similar to the SWHC. From grassland to woodland, the soil physical properties in the $0-50 \mathrm{~cm}$ soil layer partially improved, BD was significantly higher at the grassland site than at the shrubland and woodland sites, the clay and silt contents decreased significantly from grassland to shrubland to woodland and sand content showed the opposite pattern, the soil porosity was higher in the shrubland and woodland than that in the grassland. Soil texture, porosity and 
BD were the key factors affecting SWHC and soil water availability. The results of this study provide insight into the effects of vegetation restoration stage on local hydrological resources and can inform soil water management and land use planning on the Chinese Loess Plateau.

Received: 28 August 2020; Accepted: 19 April 2021

Published online: 07 May 2021

\section{References}

1. Cerdà, A., González Pelayo, Ó., Pereira, P., Novara, A., Iserloh, T. et al. The wildgeographer avatar shows how to measure soil erosion rates by means of a rainfall simulator. In Geophysical Research (2015).

2. Fu, B. J. Soil erosion and its control in the Loess Plateau of China. Soil Use Manag. 5, 76-81 (1989).

3. Lal, R. Soil carbon sequestration impacts on global climate change and food security. Science 304(5677), 1623-1627 (2004).

4. Govers, G., Van Oost, K. \& Wang, Z. Scratching the critical zone: the global footprint of agricultural soil erosion. Procedia Earth Planet. Sci. 10, 313-318 (2014).

5. Zhou, P., Wen, A., Zhang, X. \& He, X. Soil conservation and sustainable eco-environment in the Loess Plateau of China. Environ. Earth Sci. 68(3), 633-639 (2012).

6. Aldaood, A., Bouasker, M. \& Al-Mukhtar, M. Soil-water characteristic curve of lime treated gypseous soil. Appl. Clay Sci. 102, $128-138$ (2014).

7. Satyanaga, A., Rahardjo, H., Leong, E. C. \& Wang, J. Y. Water characteristic curve of soil with bimodal grain-size distribution. Comput. Geotech. 48(4), 51-61 (2013).

8. Li, X., Li, J. H. \& Zhang, L. M. Predicting bimodal soil-water characteristic curves and permeability functions using physically based parameters. Comput. Geotech. 57(4), 85-96 (2014).

9. Breda, N., Huc, R., Granier, A. \& Dreyer, E. Temperate forest trees and stands under severe drought: a review of ecophysiological responses, adaptation processes and long-term consequences. Ann. For. Sci. 63, 625-644 (2006).

10. Zhao, J., Lin, L., Yang, K., Liu, Q. \& Qian, G. Influences of land use on water quality in a reticular river network area: a case study in Shanghai, China. Landsc. Urban Plan. 137, 20-29 (2015).

11. McIntosh, J. C. \& Horne, D. J. Causes of repellency: I. The nature of the hydrophobic compounds found in a New Zealand development sequence of yellow-brown sands. In Proceedings of the 2nd National Water Repellency Workshop, 1-5 August, Perth, Western Australia, 8-12 (1994).

12. de Jonge, L. W., Moldrup, P. \& Jacobsen, O. H. Soil-water content dependency of water repellency in soils: effect of crop type, soil management, and physical-chemical parameters. Soil Sci. 172, 577-588 (2007).

13. Hallett, P. D., Ritz, K. \& Wheatley, R. E. Microbial derived water repellency in golf course soil. Int. Turfgrass Soc. Res. J. 9, 518-524 (2001).

14. Caravaca, F., Masciandaro, G. \& Ceccanti, B. Land use in relation to soil chemical and biochemical properties in a semiarid Mediterranean environment. Soil Till. Res. 68(1), 23-30 (2002).

15. Li, H., Yan, F. C., Jiao, J. Y., Tang, B. Z. \& Zhang, Y. F. Soil water availability and holding capacity of different vegetation types in hilly-gullied region of the loess plateau. Acta Ecol. Sin. 38(11) (2018).

16. Ritchie, J. T. Soil water availability. Plant Soil 58(58), 327-338 (1981).

17. Wan, S., Norby, R. J., Ledford, J. \& Weltzin, J. F. Responses of soil respiration to elevated $\mathrm{CO}_{2}$, air warming, and changing soil water availability in a model old-field grassland. Glob. Change Biol. 13(11), 2411-2424 (2007).

18. An, S. et al. Soil quality degradation processes along a deforestation chronosequence in the Ziwuling area, China. CATENA 75(3), 248-256 (2008).

19. Wang, K. B., Shao, R. X. \& Shangguan, Z. P. Changes in species richness and community productivity during succession on the Loess Plateau (China). Pol. J. Ecol. 58(3), 501-510 (2010).

20. Wang, Y., Shao, M. \& Shao, H. A preliminary investigation of the dynamic characteristics of dried soil layers on the Loess Plateau of China. J. Hydrol. 381(1-2), 9-17 (2010).

21. Reatto, A., Silva, E. M. D., Bruand, A., Martins, E. S. \& Lima, J. E. F. W. Validity of the centrifuge method for determining the water retention properties of tropical soils. Soil Sci. Soc. Am. J. 72(6), 1547-1553 (2008).

22. Jia, G. M., Cao, J., Wang, C. Y. \& Wang, G. Microbial biomass and nutrients in soil at the different stages of secondary forest succession in Ziwuling northwest China. For. Ecol. Manag. 217, 117-125 (2005).

23. Ghanbarian-Alavijeh, B. \& Millán, H. The relationship between surface fractal dimension and soil water content at permanent wilting point. Geoderma 151(3-4), 224-232 (2009).

24. Wang, M. B., Chai, B. F., Li, H. J. \& Feng, C. P. Soil water holding capacity and soil available water in plantations in the loess region. Sci. Silvae Sin. 35(2), 7-14 (1999).

25. Yang, L., Wei, W., Chen, L. D. \& Mo, B. Response of deep soil moisture to land use and afforestation in the semi-arid Loess Plateau, China. J. Hydrol. 475(6), 111-122 (2012).

26. Huang, J. H., Liao, Y. C., Gao, M. S. \& Yin, R. J. Effects of tillage and mulching on orchard soil moisture content and temperature in Loess Plateau. Chin. J. Appl. Ecol. 20(11), 2652-2658 (2009).

27. Borken, W., Savage, K., Davidson, E. A. \& Trumbore, S. E. Effects experimental drought on soil respiration and radiocarbon efflux from a temperate forest soil. Glob. Change Biol. 12, 177-193 (2006).

28. Scott-Denton, L. E., Rosenstiel, T. N. \& Monson, R. K. Differential controls by climate and substrate over the heterotrophic and rhizospheric components of soil respiration. Glob. Change Biol. 12(12), 205-216 (2006).

29. Zhang, Y. W., Deng, L., Yan, W. M. \& Shangguan, Z. P. Interaction of soil water storage dynamics and long-term natural vegetation succession on the Loess Plateau, China. CATENA 137, 52-60 (2016).

30. Zhao, S. W., Zhao, Y. G. \& Wu, J. S. Quantitative analysis of soil pores under natural vegetation successions on the Loess Plateau. Sci. China Earth Sci. 53, 617-625 (2010).

31. Udawatta, R. P. \& Anderson, S. H. Ct-measured pore characteristics of surface and subsurface soils influenced by agroforestry and grass buffers. Geoderma 145(3-4), 381-389 (2008).

32. Honda, E. A. \& Durigan, G. Woody encroachment and its consequences on hydrological processes in the Savannah. Philos. Trans. R. Soc. B 371(1703), 20150313 (2016).

33. Zhang, Y. W. \& Shangguan, Z. P. Interaction of soil water storage and stoichiometrical characteristics in the long-term natural vegetation restoration on the Loess Plateau. Ecol. Eng. 116, 7-13 (2018).

34. Wang, Z. H. et al. Effects of plant species diversity on soil conservation and stability in the secondary succession phases of a semihumid evergreen broadleaf forest in China. J. Soil Water Conserv. 67, 311-320 (2012).

35. Yang, L., Wei, W., Chen, L. D. \& Wang, J. L. Response of temporal variation of soil moisture to vegetation restoration in semi-arid Loess Plateau, China. CATENA 115, 123-133 (2014).

36. Wang, L., Mu, Y., Zhang, Q. F. \& Jia, Z. K. Effects of vegetation restoration on soil physical properties in the wind-water erosion region of the northern Loess Plateau of China. Clean: Soil, Air, Water 40(1), 7-15 (2012). 
37. Deng, L., Wang, K. B., Chen, M. L., Shangguan, Z. P. \& Sweeney, S. Soil organic carbon storage capacity positively related to forest succession on the Loess Plateau, China. CATENA 110, 1-7 (2013).

38. Zhang, Y. W. \& Shangguan, Z. P. The coupling interaction of soil water and organic carbon storage in the long vegetation restoration on the Loess Plateau. Ecol. Eng. 91, 574-581 (2016).

39. Luo, Y. Q. et al. Progressive nitrogen limitation of ecosystem responses to rising atmospheric carbon dioxide. Bioscience 54, 731-739 (2004).

\section{Acknowledgements}

This study was sponsored by the National Natural Science Foundation of China (41807520, 41671511, 41771549, 32060297), the Research Project of Yan'an University (YDQ2018-21), the Doctor's Scientific Research Startup Project (YDBK2017-25), and the Innovation Capability Support Program of Shaanxi (2020KJXX-009).

\section{Author contributions}

Y.Z., C.L. and Z.S. conceived and designed the research; Y.Z., J.W. and K.W. performed the experiments; Y.Z. analyzed the data; Y.Z. and S.Z. wrote and edited the manuscript.

\section{Competing interests}

The authors declare no competing interests.

\section{Additional information}

Correspondence and requests for materials should be addressed to Y.Z. or C.L.

Reprints and permissions information is available at www.nature.com/reprints.

Publisher's note Springer Nature remains neutral with regard to jurisdictional claims in published maps and institutional affiliations.

(c) (i) Open Access This article is licensed under a Creative Commons Attribution 4.0 International

License, which permits use, sharing, adaptation, distribution and reproduction in any medium or format, as long as you give appropriate credit to the original author(s) and the source, provide a link to the Creative Commons licence, and indicate if changes were made. The images or other third party material in this article are included in the article's Creative Commons licence, unless indicated otherwise in a credit line to the material. If material is not included in the article's Creative Commons licence and your intended use is not permitted by statutory regulation or exceeds the permitted use, you will need to obtain permission directly from the copyright holder. To view a copy of this licence, visit http://creativecommons.org/licenses/by/4.0/.

(C) The Author(s) 2021 